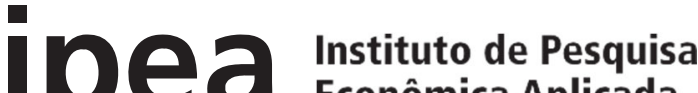 Econômica Aplicada
}

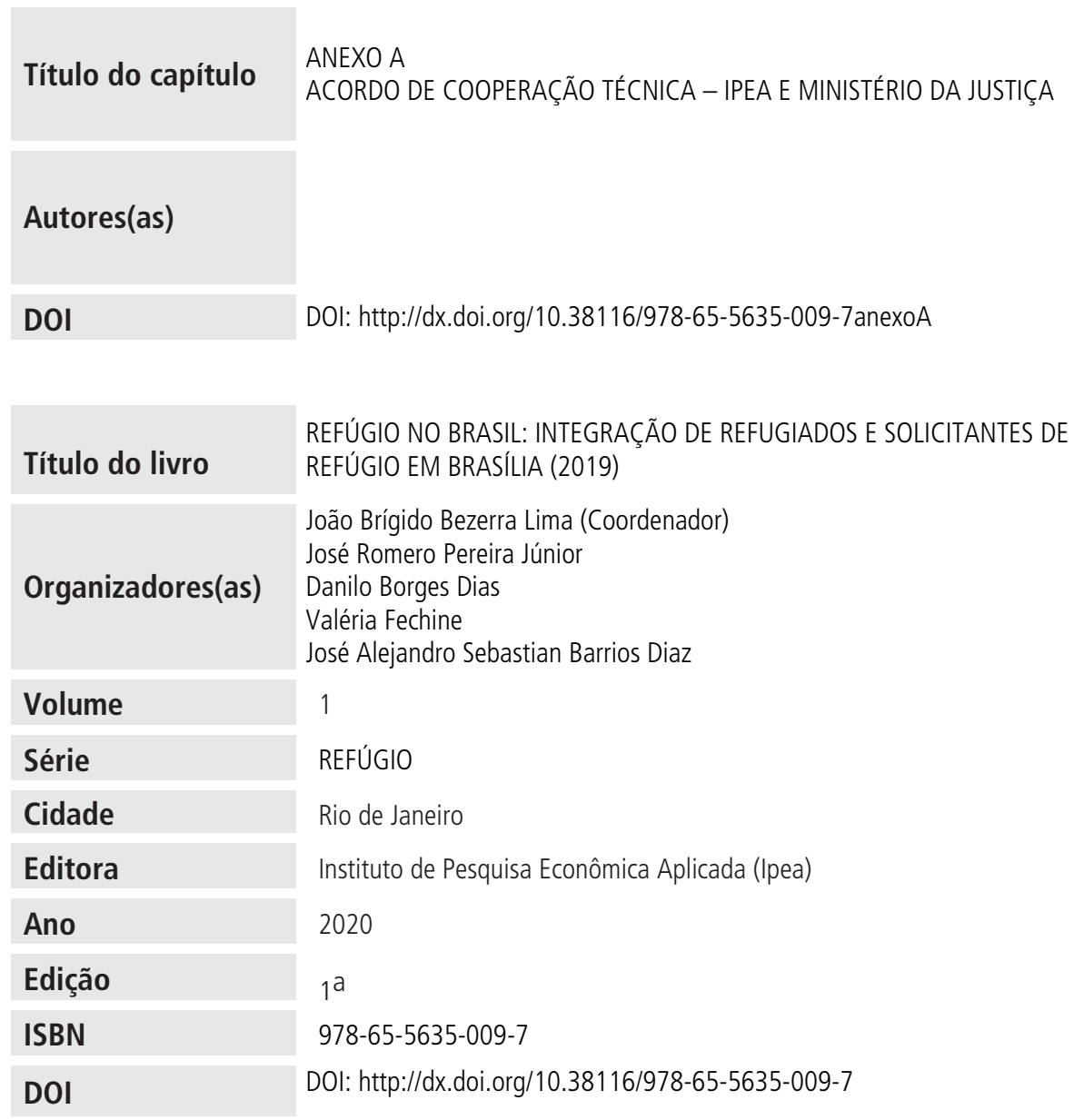

(C) Instituto de Pesquisa Econômica Aplicada - ipea 2020

As publicações do Ipea estão disponíveis para download gratuito nos formatos PDF (todas) e EPUB (livros e periódicos). Acesse: http://www.ipea.gov.br/portal/publicacoes

As opiniões emitidas nesta publicação são de exclusiva e inteira responsabilidade dos autores, não exprimindo, necessariamente, o ponto de vista do Instituto de Pesquisa Econômica Aplicada ou do Ministério da Economia.

É permitida a reprodução deste texto e dos dados nele contidos, desde que citada a fonte. Reproduções para fins comerciais são proibidas. 
ANEXO A'

\section{ACORDO DE COOPERAÇÃO TÉCNICA - IPEA E MINISTÉRIO DA JUSTIÇA}

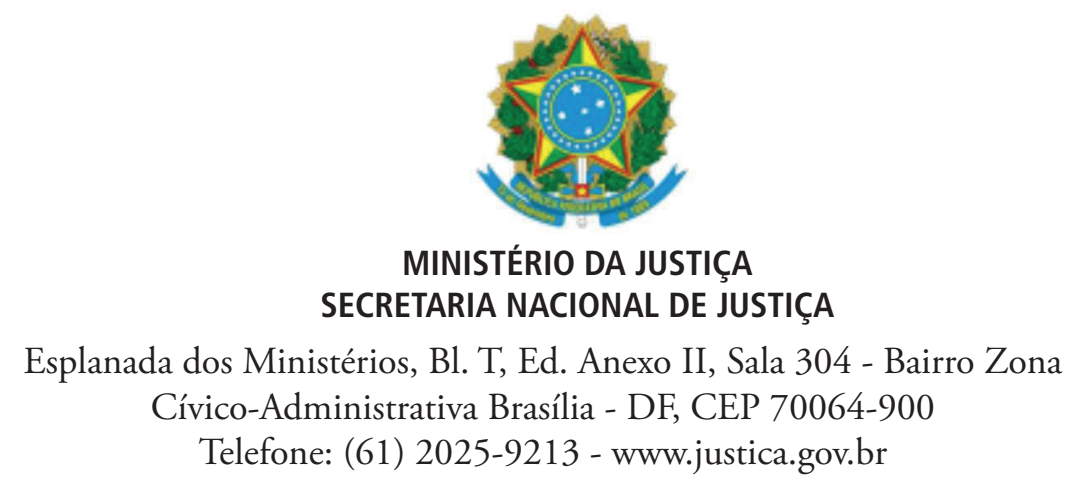

ACORDO DE COOPERAÇÃO TÉCNICA № 6/2018/SNJ

Processo Np 08018.004147/2017-48

ACORDO DE COOPERAÇÃO TÉCNICA QUE ENTRE SI CELEBRAM O INSTITUTO DE PESQUISA ECONÔMICA APLICADA - IPEA E A UNIÁO, POR INTERMÉDIO DO MINISTÉRIO DA JUSTIÇA, POR MEIO DA SECRETARIA NACIONAL DE JUSTIÇA, VISANDO ESTABELECER CONDIÇÓES À IMPLEMENTAÇÃO DE AÇÓES CONJUNTAS QUE ASSEGUREM A REALIZAÇÃO DE ESTUDOS E PESQUISAS EM ÁREAS DE MÚTUO INTERESSE, PARA OS FINS QUE ESPECIFICA.

O INSTITUTO DE PESQUISA ECONÔMICA APLICADA, Fundação Pública Federal com estatuto aprovado pelo Decreto $\mathrm{n}^{-} 7.142$, de 29 de março de 2010, publicado no Diário Oficial da Uniāo nº 60, de 30 de março de 2010, Seção I, página 18, com sede na Cidade de Brasília - DF, no Setor Bancário Sul, Edifício BNDES, inscrito no CNPJ/MF sob o no 33.892.175/0001 00, doravante denominado IPEA, neste ato representado por seu presidente, ERNESTO

1. DOI: http://dx.doi.org/10.38116/978-65-5635-009-7anexoA 
LOZARDO, brasileiro, casado, economista, residente e domiciliado em Brasília, Identidade no 3.498 .854 expedida pela SSP/SP, inscrito no CPF/MF sob o no 232.398.838-72, nomeado pela Portaria no 862 de 31 de maio de 2016, publicada no Diário Oficial da Uniāo no 103, de 01 de junho de 2016, de um lado, e, de outro lado a União, por intermédio do Ministério da Justiça - MJ, por meio da SECRETARIA NACIONAL DE JUSTIÇA, com sede na Esplanada dos Ministérios, Bloco T, Edifício Sede, 4ํandar, Brasília/DF, inscrita no CNPJ/MF 07.100.754/0001-62 doravante denominado SNJ, neste ato representado pelo Secretário Nacional de Justiça, LUIZ PONTEL DE SOUZA, Identidade no 701.884 - 1861 expedida pela SSP/RS, inscrito no CPF/MF sob o $\mathrm{n}^{\mathrm{o}}$ 521.028.589-87, nomeado pela Portaria no 179 , publicado no Diário Oficial da União de 7 de março de 2018, página 01 , Seção 02, tendo em vista o processo administrativo IPEA no $03001.002083 / 2018-97$ e o processo administrativo SNJ no 08018.004147/2017-48 resolvem, com base na Lei no 8666/93, celebrar o presente Acordo de Cooperaçáo Técnica, mediante as seguintes cláusulas e condições:

\section{CLÁUSULA PRIMEIRA - DO OBJETO}

O presente acordo visa estabelecer o suporte legal da cooperação técnica entre o Ipea e a SNJ sobre a temática da cooperação técnica, a fim de estimular as atividades relacionadas com a investigação, a análise, a promoção e a divulgação de políticas e de processos afetos aos refugiados e aos solicitantes de reconhecimento da condiçấo de refugiado no Brasil.

\section{CLÁUSULA SEGUNDA - DOS OBJETIVOS}

O objeto do presente acordo será cumprido mediante a realização de açôes conjuntas pelas quais se buscarão:

I - Fomentar a discussão, o intercâmbio de informação e a articulação entre a SNJ e o Ipea em estudos e pesquisas sobre investigação, análise, promoção e divulgação de políticas e de processos afetos aos refugiados e aos solicitantes de reconhecimento da condiçáo de refugiado no Brasil.

II - Promover estudos técnicos, pesquisas e ferramentas que visem o monitoramento e a avaliação de informação e a articulação sobre a temática do refúgio no Brasil.

III - Promover a divulgação dos resultados obtidos com esta cooperação por meio de publicaçôes, seminários e workshops. 


\section{CLÁUSULA TERCEIRA - DO PLANO DE TRABALHO}

A operacionalização do objeto se dará mediante plano de trabalho, parte integrante deste instrumento, elaborado em comum acordo pelos partícipes, devendo ser aprovado pelas respectivas autoridades signatárias, no ato da formalização do acordo.

Parágrafo primeiro. O Plano de Trabalho contempla o detalhamento das atividades, o cronograma de execução e as metas do Acordo de Cooperação Técnica.

Parágrafo segundo. O cronograma constante do Plano de Trabalho poderá sofrer alterações e especificações por meio de acordo mútuo entre os partícipes.

\section{CLÁUSULA QUARTA - DAS OBRIGAÇÕES DO INSTITUTO DE PESQUISA ECONÔMICA APLICADA - IPEA}

Constituem-se obrigações do Ipea para o desenvolvimento das ações previstas no âmbito deste Acordo:

I - Envidar esforços para cooperar plenamente com a SNJ, sempre que assim o for solicitado;

II - Assegurar o acesso aos documentos e registros à SNJ, observadas as regulaçóes existentes;

III - Disponibilizar apoio técnico à realização dos trabalhos a serem desenvolvidos no âmbito do presente acordo;

IV - Observar as condiçốes de liberação ou transmissão a terceiros de documentos, informaçōes e outros dados obtidos na implementação do presente acordo;

V - Implementar, monitorar e avaliar o Plano de Trabalho;

VI - Supervisionar a elaboração dos estudos técnicos e levantamentos previstos no Plano de Trabalho;

VIII - Divulgar os resultados obtidos a partir deste acordo;

IX - Prover informaçốes técnicas, sempre que necessário, para a elaboração de estudos e levantamentos essenciais à implementação do Plano de Trabalho;

X - Criar, quando necessário, condiçóes de natureza legal, administrativa, técnica e participativa para o desenvolvimento das atividades constantes do Plano de Trabalho.

\section{CLÁUSULA QUINTA - DAS OBRIGAÇÕES DA SECRETARIA NACIONAL DE JUSTIÇA}

Constituem-se obrigaçóes da SNJ para o desenvolvimento das ações previstas no âmbito deste acordo: 
I - Envidar esforços para cooperar plenamente com o Ipea, sempre que assim o for solicitado;

II - Assegurar o acesso aos documentos e registros ao Ipea, observadas as regulações;

III - Observar as condiçôes de liberação ou transmissão a terceiros de documentos existentes, informaçôes e outros dados obtidos na implementação do presente acordo;

IV - Monitorar e avaliar o Plano de Trabalho;

V - Promover a integração entre atores de importância para o desenvolvimento do Plano de Trabalho;

VI - Apoiar a divulgação dos resultados obtidos a partir deste acordo;

VII - Prover informaçóes técnicas, sempre que necessário, para a elaboração de estudos e levantamentos essenciais à implementação do Plano de Trabalho;

VIII - Criar, quando necessário, condiçóes de natureza legal, administrativa, técnica e participativa para o desenvolvimento das atividades constantes do Plano de Trabalho.

\section{CLÁUSULA SEXTA - DA VIGÊNCIA}

O presente Acordo de Cooperação Técnica vigorará pelo prazo de 2 (dois) anos, entrando em vigor na data de sua assinatura, podendo ser renovado por igual período, mediante a formalização de termo aditivo.

\section{CLÁUSULA SÉTIMA - DOS RECURSOS ORÇAMENTÁRIOS E FINANCEIROS}

$\mathrm{O}$ presente instrumento não envolve transferência de recursos orçamentários e financeiros entre os partícipes.

Parágrafo único. As ações que envolvam parcerias específicas e compartilhamento de recursos físicos e financeiros entre os partícipes serão efetivadas mediante a formalização, a qualquer tempo, de instrumentos específicos, segundo a natureza de cada uma, observados os dispositivos legais pertinentes a cada caso e as negociaçóes entre os partícipes, em que será detalhada a participação orçamentária e financeira de cada um dos signatários.

\section{CLÁUSULA OITAVA - DOS RECURSOS HUMANOS}

Os recursos humanos utilizados pelas partes nas atividades inerentes ao presente Acordo não sofrerão qualquer alteraçáo na sua vinculação funcional com as entidades de origem, às quais cabe responsabilizar-se por todos os encargos de natureza trabalhista, previdenciária, fiscal e securitária das açóes daí decorrentes. 


\section{CLÁUSULA NONA - DO SIGILO DAS INFORMAÇÕES}

Os partícipes, bem como seus representantes e funcionários, e quaisquer pessoas que em seu nome estejam envolvidas no manuseio das informaçóes, comprometem-se, sem prejuízo da infração penal cabível, quando da violação do disposto na presente cláusula, a:

I - Observar e manter, em toda a sua extensão, o sigilo das informaçóes compartilhadas; e

II - Adotar as medidas de segurança adequadas, no âmbito das atividades sob seu controle, para a manutenção do sigilo das informaçōes.

\section{CLÁUSULA DÉCIMA - DA PROPRIEDADE INTELECTUAL}

Para a execução do presente acordo, os partícipes se comprometem a respeitar, sempre e em todo momento, os direitos autorais e de propriedade intelectual, e a confidencialidade exigida pela contraparte no intercâmbio de informaçóes e em quaisquer outras atividades.

Parágrafo primeiro. Todo e qualquer direito autoral ou de propriedade intelectual relativo a qualquer produto desenvolvido ou criado no âmbito desse acordo, inclusive quanto aos trabalhos editados em conjunto decorrentes de estudos, pesquisas e levantamentos realizados serão compartilhados entre os partícipes.

Parágrafo segundo. Os partícipes se comprometem a não utilizar os insumos recebidos da contraparte para fins distintos àqueles acordados no presente instrumento, salvo quando devidamente autorizado, por escrito e com antecedência de quinze (15) dias, pelo partícipe proprietário dos insumos ou representante deste.

Parágrafo terceiro. Os partícipes poderão utilizar os resultados e produtos do presente acordo em suas atividades, sempre atentos a não configuração de desvio de finalidade e citando o presente instrumento como fonte.

Parágrafo quarto. Os materiais preexistentes do Ipea, porventura utilizados nos trabalhos objeto deste Acordo, serão protegidos pela Lei de Direitos Autorais, continuando sob a propriedade do Ipea.

\section{CLÁUSULA DÉCIMA PRIMEIRA - DA DIVULGAÇÃO}

Os partícipes deverão dar, de forma pública e impessoal, ampla divulgação das açôes e dos resultados alcançados em decorrência deste acordo, restando vedada a utilização de nomes, símbolos ou imagens que caracterizem promoção pessoal de agentes públicos.

Parágrafo único. Toda ação promocional relacionada com o objeto deste acordo deverá ser nominada com as instituições envolvidas. 


\section{CLÁUSULA DÉCIMA SEGUNDA - DOS REPRESENTANTES}

Para gerenciar a execução das atividades decorrentes deste ACT, o Ipea será representado pela Diretoria de Estudos e Relaçóes Econômicas e Políticas Internacionais - DINTE e a SNJ pela Coordenação Geral do Comitê Nacional para Refugiados, que indicarão os servidores responsáveis pelo acompanhamento, avaliação, supervisão e fiscalização da execução.

\section{CLÁUSULA DÉCIMA TERCEIRA - DA PUBLICAÇÃO}

Caberá ao Ipea providenciar a publicação do presente acordo, e seus eventuais termos aditivos, em extrato, no Diário Oficial da União, nos termos do parágrafo único do artigo 61 da Lei no 8.666, de 21 de junho de 1993.

\section{CLÁUSULA DÉCIMA QUARTA - DAS ALTERAÇÕES}

Este ACT poderá ser alterado de comum acordo entre os partícipes, durante a sua vigência, mediante termo aditivo devidamente justificado, vedada a alteraçáo da natureza do objeto.

\section{CLÁUSULA DÉCIMA QUINTA - DA DENÚNCIA}

Este acordo poderá ser denunciado pelos partícipes a qualquer tempo. A intenção de denunciar este acordo deverá ser fundamentada e comunicada por escrito, com antecedência mínima de 90 (noventa) dias, ficando as partes responsáveis pelas obrigaçóes decorrentes do tempo de vigência do ACT.

\section{CLÁUSULA DÉCIMA SEXTA - RESCISÃO}

A inexecução das obrigaçóes prevista no Plano de Trabalho ensejará a rescisão do acordo firmado. O partícipe que der causa à rescisão perderá em desfavor do outro os direitos sobre as ações e produtos já realizados ou em andamento.

\section{CLÁUSULA DÉCIMA SÉTIMA - DO FORO}

Os partícipes comprometem-se a submeter eventuais controvérsias decorrentes do presente instrumento à conciliação que será promovida pela Advocacia-Geral da União, na Câmara de Conciliação e Arbitragem da Administração Federal, conforme Decreto no 7.392 , de 13 de dezembro de 2010. Náo logrado êxito a conciliaçáo, será competente para dirimir as questóes decorrentes deste Acordo, que não possam ser resolvidas pela mediação administrativa, o foro da Justiça Federal, Seção Judiciária do Distrito Federal, por força do inciso I do art. 109 da Constituição Federal. 
E, por estarem de acordo, os partícipes firmam o presente instrumento em 2 (duas) vias de igual teor e forma em português, perante as testemunhas abaixo, para que produza os efeitos jurídicos e legais em juízo e fora dele.

Brasília, de setembro de 2018.

\section{ERNESTO LOZARDO}

Presidente do IPEA
LUIZ PONTEL DE SOUZA

Secretário Nacional de Justiça

TESTEMUNHAS:

\begin{tabular}{|l|l|l|l|}
\hline 1. & & 2 & \\
\cline { 2 - 3 } & & \\
\hline NOME: & NOME: \\
\hline RG: & RG: \\
\hline CPF: & CPF: \\
\hline
\end{tabular}

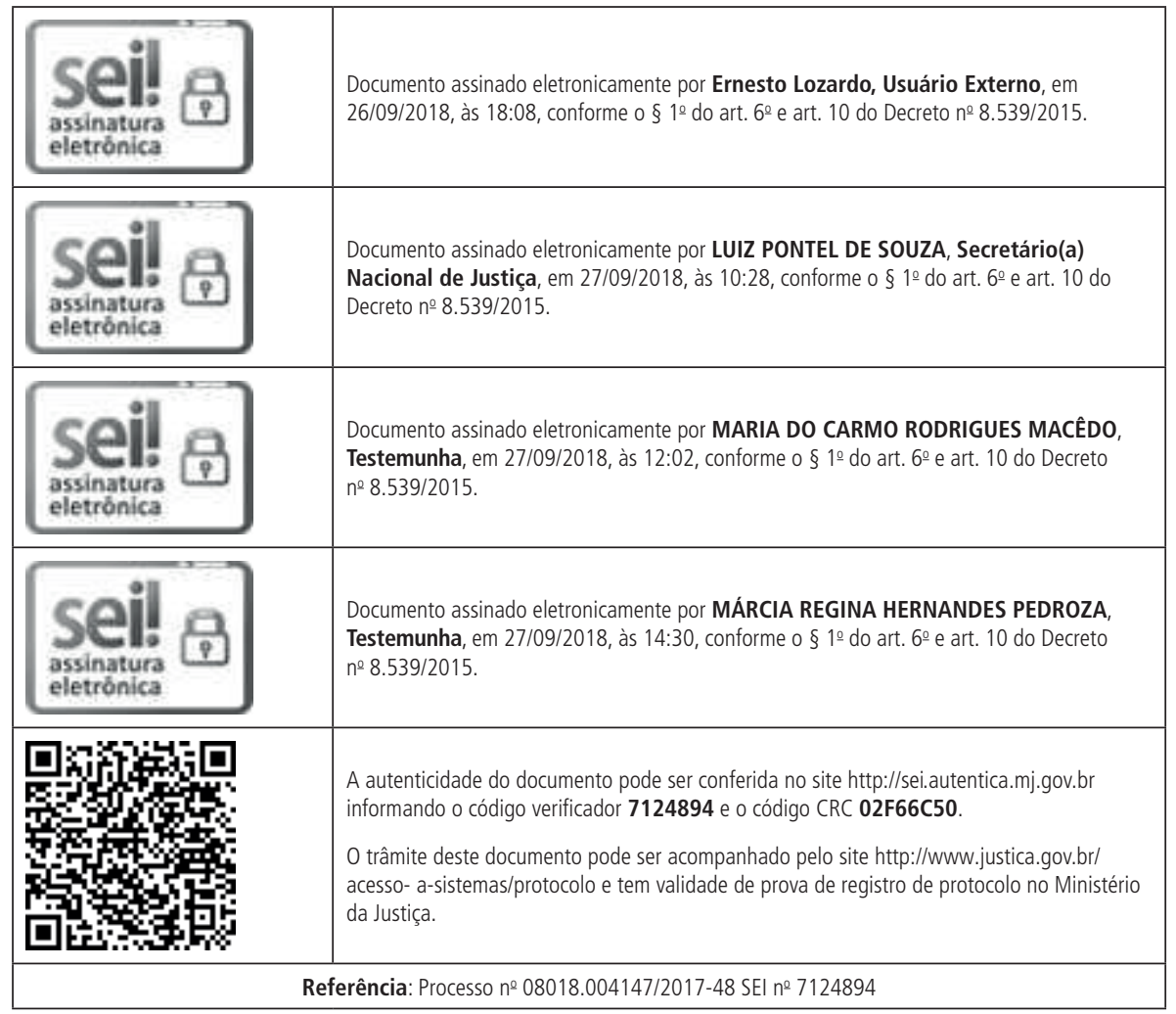


